\title{
Function and Mechanism of RGD in Bone and Cartilage Tissue Engineering
}

\author{
Meng Yang ${ }^{1,2,3+}$, Zheng-Chu Zhang ${ }^{4 \dagger}$, Yan Liu ${ }^{1,2 \dagger}$, You-Rong Chen ${ }^{1,2}$, Rong-Hui Deng ${ }^{1,2}$, \\ Zi-Ning Zhang ${ }^{1,2}$, Jia-Kuo Yu ${ }^{1,2,3 *}$ and Fu-Zhen Yuan ${ }^{1,2 *}$
}

${ }^{1}$ Sports Medicine Department, Beijing Key Laboratory of Sports Injuries, Peking University Third Hospital, Beijing, China, ${ }^{2}$ Institute of Sports Medicine of Peking University, Beijing, China, ${ }^{3}$ School of Clinical Medicine, Weifang Medical University, Weifang, China, ${ }^{4}$ Beijing National Laboratory for Molecular Sciences, Center for Soft Matter Science and Engineering, Key Laboratory of Polymer Chemistry and Physics of Ministry of Education, College of Chemistry and Molecular Engineering, Peking University, Beijing, China

Bone and cartilage injury is common, tissue engineered scaffolds are potential means to repair. Because most of the scaffold materials used in bone and cartilage tissue engineering are bio-inert, it is necessary to increase the cellular adhesion ability of during tissue engineering reconstruction. The Arginine - Glycine - Aspartic acid (ArgGly-Asp, RGD) peptide family is considered as a specific recognition site for the integrin receptors. Integrin receptors are key regulators of cell-cell and cell-extracellular microenvironment communication. Therefore, the RGD polypeptide families are considered as suitable candidates for treatment of a variety of diseases and for the regeneration of various tissues and organs. Many scaffold material for tissue engineering and has been approved by US Food and Drug Administration (FDA) for human using. The application of RGD peptides in bone and cartilage tissue engineering was reported seldom. Only a few reviews have summarized the applications of RGD peptide with alloy, bone cements, and PCL in bone tissue engineering. Herein, we summarize the application progress of RGD in bone and cartilage tissue engineering, discuss the effects of structure, sequence, concentration, mechanical stimulation, physicochemical stimulation, and time stimulation of RGD peptide on cells differentiation, and introduce the mechanism of $R G D$ peptide through integrin in the field of bone and cartilage tissue engineering.

Keywords: (adhesion peptide) RGD, Arg-Gly-Asp, bone, cartilage, tissue engineering

\section{INTRODUCTION}

Bone and cartilage injuries are common and frequent (Deng et al., 2019), and mature articular cartilage is limited in its ability to repair itself (Krishnan and Grodzinsky, 2018). eventually lead to osteoarthritis, which causes joint pain (Barnett, 2018). Recently, scaffolds with composed with seed cells became a promising method for bone and cartilage repair (Daly et al., 2017; Shadjou et al., 2018; Zhang et al., 2020). Seed cells are key to tissue engineering, as autologous cartilage and huge bone defect lacks the ability to regenerate, and seed cells could enhance tissue repair by producing extracellular matrix (ECM) and growth factors (Zhang et al., 2016). Scaffolds not only have basic functions, such as supporting and filling, but also promote cell adhesion, proliferation, and differentiation.

In recent years, the use of tissue engineering scaffolds to repair bone and cartilage damage developed quickly. According to the source of scaffolds, they can be divided into natural materials 
A<smiles>N=C(N)NCCC[C@H](N)C(=O)NCC(=O)NC(CC(=O)O)C(=O)O</smiles>

C<smiles>N=C(N)NCCCC(NC(=O)CN)C(=O)NCC(=O)NCC(CC(=O)O)C(=O)NC(CO)C(=O)O</smiles>

$\mathbf{E}$<smiles>N=C(N)NCCCC(NC(=O)C(N)Cc1ccc(O)cc1)C(=O)NCC(=O)NC(CC(=O)O)C(=O)NC(CO)C(=O)O</smiles>

B<smiles>N=C(N)NCCCC(N)C(=O)NCC(=O)NC(CC(=O)O)C(=O)NC(CO)C(=O)O</smiles>

D<smiles>N=C(N)NCCCC1NC(=O)C(CCCCN)NC(=O)CNC(=O)C(Cc2ccccc2)NC(=O)C(CC(=O)O)NC(=O)C1NC(=O)O</smiles>

$\mathbf{F}$<smiles>N=C(N)NCCCCC(NC(=O)CNC(=O)C(Cc1ccc(O)cc1)NC(=O)CNC(=O)C(CS)NC(=O)CN)C(=O)NCC(=O)NC(CC(=O)O)C(=O)NC(CO)C(=O)N1CCCC1C(=O)NCC(=O)O</smiles>

FIGURE 1 | Chemical structures. (A) RGD; (B) RGDS; (C) GRGDS; (D) C (RGDfk); (E) YRGDS; (F) GCGYGRGDSPG.

and synthetic materials. Natural materials used for bone and cartilage repair include collagen, hyaluronic acid, fibrin glue, chitosan, agarose and alginic acid. They have good biocompatibility, cell adhesion, and degradation products are non-toxic physiological products (Wang et al., 2021). However, they also have many disadvantages, such as: limited source, difficult processing, poor mechanical strength, and possible disease transmission problems (Rahimi et al., 2021). To solve these problems, researchers have made many attempts in synthetic materials. Synthetic materials commonly used in bone and cartilage tissue engineering include alloys, bone cements, PEG polymers, and poly ( $\varepsilon$-caprolactone) (PCL) (Jiang et al., 2021). Synthetic materials indeed solve the problems of natural materials, but they usually have limited cellular adhesion properties.

Cell adhesion is an important condition for long-term survival of transplanted cells (Lee et al., 2015). Due to the bio-inert of most synthetic materials, cell adhesion peptide RGD is usually integrated into biomaterials to achieve better cell adhesion. RGD combined with PCL (Richbourg et al., 2019; Alipour et al., 2020), titanium alloy
(Dard et al., 2000; Alipour et al., 2020), and calcium phosphate cements (CPCs) (Lin et al., 2019) had been reported. Many scaffolds for tissue engineering have been approved the possibility to be used in clinic due to high-water absorption ability mimicking natural tissues, easy precision regulation, and low immunogenicity (Chin et al., 2018; Di Palma et al., 2021). PEG is also bio-inert and is often combined with RGD for tissue engineering repair.

It is well known that RGD works through Integrin. RGD has been widely recognized as a polypeptide that enhances cell adhesion and cell viability, its effect on cell differentiation is highly controversial (Burdick and Anseth, 2002; Benoit and Anseth, 2005; Yang et al., 2005; Vonwil et al., 2010; Jäger et al., 2013; Callahan et al., 2013b; Kim et al., 2015). Integrins are a superfamily of cell-adhesion receptors that bind to cell surface ligands (Takada et al., 2007), is a transmembrane receptor composed of $\alpha$ and $\beta$ subunits, which is closely involved in many important physiological activities of cells, such as cell proliferation (Marsico et al., 2018), cell adhesion (Ellis and Tanentzapf, 2010), cell apoptosis (Wei et al., 2020), and cell differentiation (Shen et al., 2019). 
This review focuses on recent advances in bone and cartilage tissue engineering based on RGD-modified scaffolds. In addition to analyzing the possible influence of different RGD peptide sequence structure on bone and cartilage tissue engineering, we also deeply discussed mechanism of the biological effects of RGD peptide by the way of binding to different integrin receptors.

\section{DIFFERENT STRUCTURES AND SEQUENCES OF RGD}

RGD is a cell adhesion motif found in many ECM (Colombo and Bianchi, 2010). In 1984, Pierschbacher et al. first discovered the RGD peptide (Figure 1A) in fibronectin (Pierschbacher and Ruoslahti, 1984). Subsequently, it was found that RGD peptides were widely present in fibronectin, laminin, fibrinogen, osteopontin and vitronectin (Ruoslahti, 1996). RGD can be divided into RGD and RGD polypeptide. The former is a tripeptide sequence of RGD, and the latter is a functional peptide containing RGD. In the field of bone and cartilage tissue engineering, a variety of RGD-modified hydrogels with different structures have been used for bone and cartilage repair. In the aspect of bone repair, RGD structures that are widely used include RGDS (Benoit and Anseth, 2005) (Figure 1B), GRGDS (Paxton et al., 2009) (Figure 1C), c (RGDfk) (Tang et al., 2010; Bell et al., 2011; Peng et al., 2011; Jäger et al., 2013; Ye et al., 2015; Ye et al., 2016) (Figure 1D) and YRGDS (Burdick and Anseth, 2002; Yang et al., 2005; Steinmetz and Bryant, 2011; Reid et al., 2013) (Figure 1E). What's more, RGD structures are widely used in cartilage repair, include $c$ (RGDfk) (Cao et al., 2014; Li et al., 2015a; Li et al., 2015b) (Figure 1C), YRGDS (Bryant et al., 2008; Villanueva et al., 2009; Steinmetz and Bryant, 2011; Kim et al., 2015) (Figure 1E), RGDS (Salinas et al., 2007; Kloxin et al., 2009; Callahan et al., 2013a) (Figure 1B) and GCGYGRGDSPG (Kudva et al., 2017; Kudva et al., 2018a; Kudva et al., 2018b) (Figure 1F). The detailed structure diagram is shown in Figure 1. RGD peptides are mainly divided into linear and cyclic RGD peptides. Interestingly, cyclic RGD peptides are thought to be more active than linear RGD peptides. The probable reason is that cyclic peptides are more resistant to proteolysis and can bind to integrin receptors with a higher affinity (Verrier et al., 2002; Frochot et al., 2007). In addition, the study of Heller showed that cyclic RGD is more beneficial to bone repair in vivo than linear RGD (Heller et al., 2018).

\section{THE SYNTHESIS OF RGD}

Merrifield created and developed the method of solid phase peptide synthesis (SPPS), which greatly simplified the synthesis and purification of polypeptides, greatly improved the productivity, made the synthetic synthesis of various polypeptides feasible, and provided convenience for the modification of biological materials by polypeptides.

At present, there have been many reports on the synthesis methods of RGD peptide and its analogues, including enzyme- catalyzed synthesis, solid-phase synthesis and liquid-phase synthesis. Among them, Huang (Huang et al., 2005). reported the enzyme-catalyzed synthesis method, but the catalytic activity of the enzyme was affected by a variety of factors such as the reaction solvent system, the ratio of the dosage of the reaction substrate, reaction temperature, $\mathrm{pH}$ value, and reaction time. And the reaction conditions are strict and difficult to control. Kumagai et al. (1991) reported the liquid-phase synthesis method for RGD peptide, Liquid-phase synthesis is relatively simple, rapid and cost little, but due to the large pollution, complex reaction and other reasons, people prefer to use SPPS method. SPPS method to synthesis RGD peptide and its analogues has superiority of mild reaction conditions, simple reaction operation and easy automation, but it still has the disadvantages of high cost, low yield and not suitable for mass production (Sulyok et al., 2001; Kuijpers et al., 2007).

Cyclic RGD peptide is reported to be more stable due to rigidity of the ring and low degradability by enzyme (Bogdanowich-Knipp et al., 1999). However, inducing cyclic structure to RGD peptide brings additional challenge. In tradition strategy, cyclization was performed after cleavage the peptide from resin, using different coupling reagent/base system (Frochot et al., 2007) or just using $\mathrm{NH}_{4} \mathrm{OH}$ aqueous solution (Wang et al., 2005) to cyclization. Furthermore, in Wang's work, the cyclization of pentapeptides was taken on the solid support, using benzotriazol-1-yl-oxy-tris-pyrrolidinophosphonium hexafluorophosphate (PyBOB), 1-hydroxybenzotriazole (HOBT) and N, N-Diisopropylethylamine (DIPEA) to from the cyclic peptide, while the side chain of Asp was conjugated to resin (Wang et al., 2005).

\section{THE ACTIVE SITE INTEGRIN AS THE MECHANISM OF RGD ACTION}

RGD is a specific ligand for integrins on cell membranes. Integrins on cell membranes are composed of $\alpha$ and $\beta$ subunits, which are important transmembrane receptors that mediate the attachment of cells to extracellular matrix (Figure 2A). The combination of $\alpha$ and $\beta$ subunits forms 24 kinds of integrins. Only some integrins recognize RGD sequences in natural ligands (Figure 2B), which are: $\alpha 8 \beta 1$, a5 $\beta 1$, allb $\beta 3, \alpha v \beta 1, \alpha v \beta 3, \alpha v \beta 5, \alpha v \beta 6, \alpha v \beta 8$ (Barczyk et al., 2010). Among them, $\alpha 5 \beta 1$ and $\alpha v \beta 3$ integrins play a major role in bone and cartilage repair (Figure 3 ).

RGD can block $\alpha 5 \beta 1$ and prevent the maturation of bone nodules (Moursi et al., 1996). Integrin $\alpha 5 \beta 1$ helps to recruit Mesenchymal stem cells (MSCs) to the defect site for repair. Several studies have shown that $\alpha 5 \beta 1$ can promote the osteogenic differentiation of MSCs in vitro (Hamidouche et al., 2009; Martino et al., 2009). Studies have shown that $\alpha v \beta 3$ seems to have an inhibitory effect in osteogenic differentiation (Cheng et al., 2001; Martino et al., 2009). Martino et al. found that blocking $\alpha v \beta 3$ could promote the proliferation and osteogenic differentiation of MSCs (Martino et al., 2009). Similarly, the overexpression of $\alpha \mathrm{v} \beta 3$ can inhibit proliferation and the expression of osteogenic gene bone sialoprotein, ALP, and collagen I (Cheng et al., 2001). 

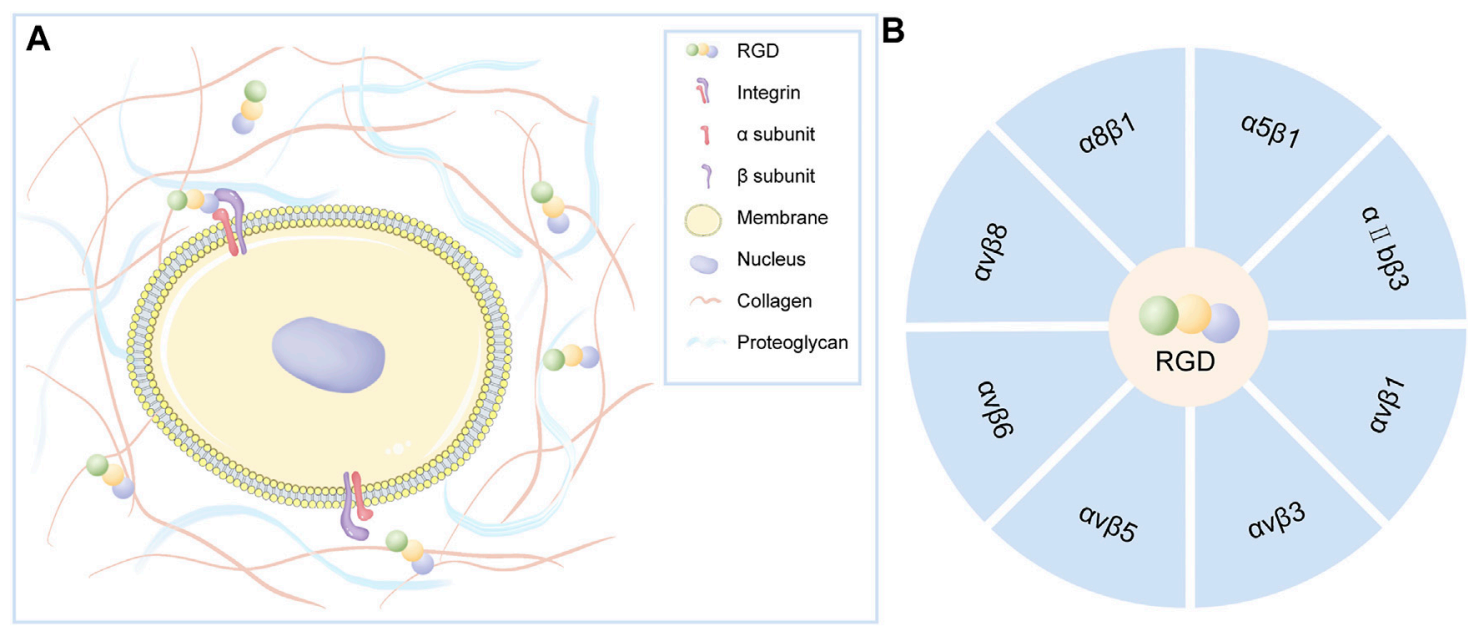

FIGURE 2 | (A) Integrins on the cell membrane are composed of $\alpha$ and $\beta$ subunits that act as transmembrane receptors mediating cell attachment to the extracellular matrix. Certain integrins can specifically recognize RGD polypeptides. (B) Integrin that specifically recognizes RGD polypeptides.

A

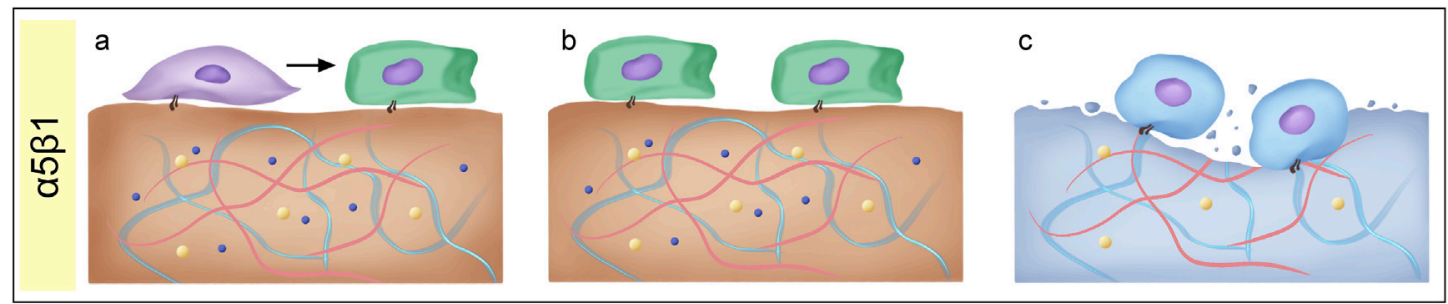

B
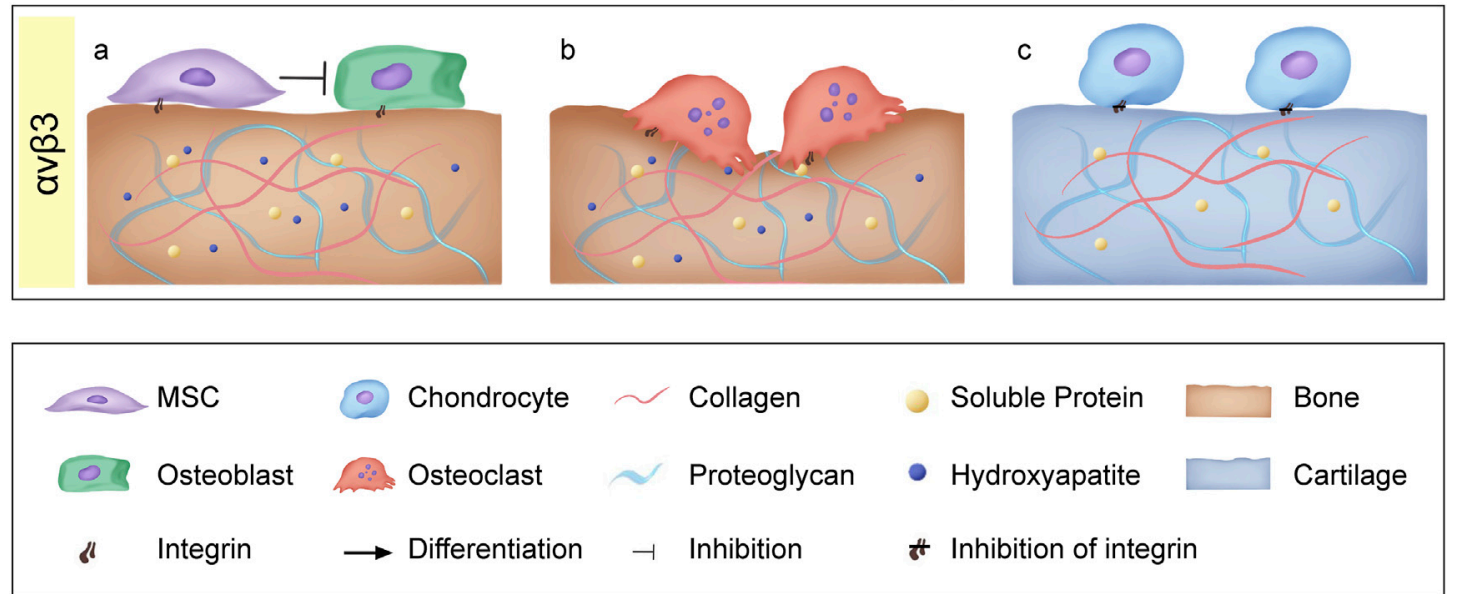

FIGURE 3 | (A) Integrins a $5 \beta 1$ : (a) $\alpha 5 \beta 1$ promote osteoblastic differentiation of mesenchymal stem cells; (b) a5 $\beta 1$ promote osteoblast proliferation and bone formation; (c) a5 $\beta 1$ also activates pro-inflammatory and catabolic responses leading to cartilage matrix degradation. (B) Integrins av $\beta 3$ : (a) $\alpha \vee \beta 3$ Inhibit MSCs proliferation and osteogenic differentiation; (b) $\alpha \vee \beta 3$ promote bone resorption; (c) Inhibition of $\alpha \vee \beta 3$ could significantly inhibit osteoarthritis (OA) inflammation and decrease OA progression.

Integrins can not only affect the differentiation of MSCs into osteoblasts, but also play an important role in bone formation and resorption. $\alpha 5 \beta 1$ integrins have been identified as essential for osteoblast survival and bone mineralization. Inhibiting the expression of $\alpha 5 \beta 1$ will lead to a low osteoblast survival rate (Dufour et al., 2008) and bone loss (Schneider et al., 2001; Dufour 
et al., 2008). Compared with the role of $\alpha 5 \beta 1$ in osteoblasts, $\alpha v \beta 3$ is mainly closely related to osteoclasts. $\alpha v \beta 3$ is an important adhesion integrin of osteoclasts, so inhibition of $\alpha v \beta 3$ will lead to osteoclast apoptosis (Horton, 1997). In addition, studies have shown that through specific antagonism of $\alpha v \beta 3$ integrin, it can inhibit bone resorption and increase bone mineral density (Horton, 2001; Cacciari and Spalluto, 2005).

RGD binding integrin is upregulated in osteoarthritic cartilage. A study has shown that the expression of integrins a $5 \beta 1$ gradually decreases during the differentiation of MSCs into cartilage (Goessler et al., 2008). Therefore, integrin a5 $\beta 1$ may affect undifferentiated MSCs, and with the progress of differentiation, it seems necessary to induce the phenotype of chondrocytes by reducing this receptor. Interestingly, Tao et al. found that by blocking a $5 \beta 1$ receptor can significantly reduce the enhancement of fibronectin (FN) on chondrogenic differentiation of chondrogenic progenitor cells (CPC) (Tao et al., 2018).

$\mathrm{OA}$ is one of the common bone and cartilage diseases, its pathological changes include cartilage erosion and loss on the joint surface (Pritzker et al., 2006). Fibronectin fragments are produced when the cartilage matrix is damaged. It's binding with a5 $\beta 1$ can activate pro-inflammatory and catabolic responses, which will lead to cartilage matrix degradation (Loeser, 2014). Furthermore, many studies have shown that $\alpha 5 \beta 1$, as RGD binding integrin, is upregulated in osteoarthritic cartilage, promoting the expression of inflammatory signals, and ultimately accelerating the development of OA (Ostergaard et al., 1998; Attur et al., 2000; Almonte-Becerril et al., 2014; Candela et al., 2016). In addition to integrin $\alpha 5 \beta 1$, normal chondrocytes also express $\alpha v \beta 3, \alpha 1 \beta 1, \alpha v \beta 5$ and $\alpha 3 \beta 1$ (Woods et al., 1994). Among them, $\alpha v \beta 3$ also plays a certain regulatory role in OA. Wang et al. shown that blocking $\alpha v \beta 3$ can significantly inhibit the inflammation of $\mathrm{OA}$ and weaken the progression of OA (Wang et al., 2019). In addition, Mukundan et al. also confirmed that $\alpha v \beta 3$ can reduce the production of inflammatory factors such as IL-1B, NO and PGE2, and negatively regulate the progression of OA (Attur et al., 2000).

\section{APPLICATION OF RGD IN BONE TISSUE ENGINEERING}

RGD interacts with specific receptors on the surface of integrin and is therefore called a stimulant of cell adhesion. It is immobilized on the polymer surface to activate cell proliferation, regulate cell metabolism and extracellular matrix synthesis (de Jonge et al., 2008). RGD is often composed into PEG hydrogels to enhance cell viability. However, researchers usually focus on RGD's ability to promote cell adhesion and proliferation. Whether RGD peptide can promote cell differentiation is still a controversial issue. In the following sections, we will discuss the effects of RGD peptides on cell differentiation in bone and cartilage tissue engineering.

The application scenarios of bone tissue engineering are mainly large-area bone defects, bone necrosis and bone nonunion caused by trauma (Kim et al., 2017). In the face of strong demand, supports represented by titanium alloy (Dard et al., 2000), PCL (Richbourg et al., 2019; Alipour et al., 2020), phosphate composites (Lin et al., 2019) and polyethylene glycol polymers (Wang et al., 2017) have been produced in the field of bone tissue engineering. These tissue engineering supports usually have high mechanical properties; whereas it's accompanied by poor cell adhesion. RGD Peptides are often added to these scaffolds to improve their cell adhesion. The results shown that titanium alloy, PCL and phosphate complexes can significantly promote bone repair and healing after adding RGD Peptides (Lin et al., 2019; Alipour et al., 2020). Among them, many studies have shown that the surface modification of RGD by titanium alloy is beneficial to the early adhesion and spread of osteoblasts, and to the proliferation and differentiation of cells in the later stage (Ferris et al., 1999; Elmengaard et al., 2005; Heller et al., 2018).

PEG hydrogel also has the disadvantage of poor cell adhesion. While titanium alloy combined with RGD had achieved good results in the field of bone repair, studies of Jäger (Jäger et al., 2013), Benoit (Benoit and Anseth, 2005) and Bell (Bell et al., 2011) showed that RGD peptide combined with polyethylene glycol hydrogel did not promote stem cell osteogenesis. It even inhibits the osteogenic differentiation of cells. Tosatti (Tosatti et al., 2004) found that RGD-containing peptide GCRGYGRGDSPG reduced enhancement of osteoblast differentiation by poly-(L-lysine)-graft-PEG-coated titanium surfaces. The results of Bell (Bell et al., 2011) showed that RGD increased the number of cells, but decreased the markers of osteoblast differentiation. Moreover, Smith believed that in continuous gradient culture, low RGD concentrations were more conducive to osteogenic differentiation than high RGD concentrations (Callahan et al., 2013c).

There are also results showing that RGD peptide combined with PEG hydrogel can promote osteogenesis. Kim found that an injectable hydrogel based on MPEG (methoxy polyethylene glycol) -PCL-RGD could promote osteogenic differentiation of stem cells. Moreover, they suggested that focal adhesion kinase (FAK) protein kinase B (AKT) and FAK extracellular signalregulated kinase (ERK) also played roles in osteogenic differentiation in the RGD-integrin-mediated pathway (Kim et al., 2020). Burdick (Burdick and Anseth, 2002) thought that compare with $0 \mathrm{mM}, 0.5 \mathrm{mM}$ RGD, $5 \mathrm{mM}$ concentration of PEGDA-RGD hydrogel had a more significant ability to promote cell mineralization. The results of Yang (Yang et al., 2005) showed that the expression of bone related markers Osteocalcin (OCN) and alkaline phosphatase (ALP) increased significantly with the increase of RGD concentration. Wong (Wong et al., 2017)' data showed that high RGD tether mobility delayed the early adhesion and spreading of human mesenchymal stem cells (hMSCs), leading to compromised osteogenic differentiation at a later stage. In contrast, hMSCs cultured on substrate with restricted RGD tether mobility, achieved either via a shorter PEG linker or magnetic force, showed significantly better adhesion, spreading, and osteogenic differentiation. Moreover, PEG-RGD regulated the osteogenic differentiation of MSCs by changing the aspect ratio and shape of cells in 2D culture (Tang et al., 2010; Peng et al., 2011). Interestingly, the results of Steinmetz (Steinmetz and 
Bryant, 2011) showed that although simple RGD inhibited osteogenic differentiation, RGD could promote osteogenesis through dynamic compression of hydrogel scaffolds. In addition, Nam (Nam et al., 2019) found that faster relaxation of RGD functionalized alginate -PEG hydrogels enhanced osteogenic differentiation of MSCs.

In conclusion, there may be three reasons for the different results. First, the RGD adhesion peptide sequences used in each study are different. Some results show that cyclic RGD has better biological activity than linear RGD; Second, different cells adopt different integrin sites, which may activate different pathways and induce the opposite results; Third, there are different types of polyethylene glycol hydrogels. Their spatial structures are different, their effects on cells are different; and the time of degradation of hydrogels is also different. The suitable degradation time of tissue engineering scaffolds is very important. The slow degradation will prevent the growth of new bone, while the fast degradation will lead to the failure of new tissue to grow in time. The results of Thoma's study showed that polyethylene glycol hydrogels with RGD had better degradability and improved bone formation (Thoma et al., 2011).

Beyond that, many studies have found that RGD polypeptide functionalized PEG-based hydrogels are very suitable scaffolds for bone tissue engineering (Nuttelman et al., 2005; Pan et al., 2014; Gao et al., 2015; Carles-Carner et al., 2018; Chahal et al., 2020). Although their results showed that the constructed hydrogel system had a significant osteogenic effect, RGD polypeptide in these hydrogel systems might mainly play the role of cell adhesion. They still lacked a control group to show that RGD promotes osteogenesis. The reasons for their conclusions are complex and most likely closely related to other components of the system that promote osteogenesis, such as: calcium phosphate composites (Chahal et al., 2020), hydroxyapatite nanoparticles (Pan et al., 2014; Carles-Carner et al., 2018), acrylated matrix metalloproteinase (MMP)-sensitive peptide (Gao et al., 2015), and ethylene glycol methacrylate phosphate (EGMP) (Nuttelman et al., 2005). It's worth noting that nanoparticles modified with RGD peptides can be used to treat diseases (Liu et al., 2018; Deng et al., 2021) or deliver specific genes (Kong et al., 2015). Bone morphogenetic protein is an important growth factor for osteogenesis, GUAN et al. utilized PEG molecules and RGD peptide (thermo-activated thiol-yne and copper-free alkyne and azide click reactions) to achieve reverse gradients and create countercurrent distributions of fibroblast growth factor 2 (FGF-2) and bone morphogenetic protein 2 (BMP-2) gradients (Guan et al., 2016).

\section{APPLICATION OF RGD IN CARTILAGE TISSUE ENGINEERING}

Once damaged, cartilage is difficult to repair due to the lack of nerves and blood vessels. There are also many studies on the treatment of cartilage defects with PEG combined with RGD tissue engineering scaffolds in recent years.

It is also controversial whether polyethylene glycol combined with RGD hydrogel promotes cell differentiation. Kudva's research in recent years showed that 150 um RGD could promote human periosteal stem cells into cartilage (Kudva et al., 2018a). It is interesting to note the same RGD sequence structure and their research of human articular cartilage cells results showed that $150 \mu \mathrm{m}$ RGD can promote cartilage cells in vitro plant regeneration (Kudva et al., 2017). It suggests different cells with the same RGD sequence will show different results of differentiation. Zhang's results also showed that RGD polypeptides could improve the function of the cartilage cells, but would cause cartilage cell hypertrophy and slightly to differentiation tendency (Zhang et al., 2015). Li (Li et al., 2015a) found that RGD peptides nanoscale spatial arrangement of cartilage cells to differentiation may also be affected, and sparse RGD spatial arrangement could reduce cartilage cells to differentiation. Li's results also showed that large RGD nano spacing could promote the differentiation of mesenchymal stem cells into cartilage (Li et al., 2015b). Moreover, the results illustrated that chondrocytes dedifferentiation were more likely to occur in the condition of larger sizes and higher aspect ratios (Cao et al., 2014).

Contrary to the results of Kim (Kim et al., 2015) and Vonwil (Vonwil et al., 2010), Smith believed that the cartilage phenotype and extracellular matrix secretion of human chondrocytes are inhibited with the increase of RGD concentration (Callahan et al., 2013b). Some scholars believed that appropriate RGD concentration, mechanical stimulation, physicochemical stimulation, or time stimulation was the key to promote the chondrogenic phenotype of cells. Liu (Liu et al., 2010) found that under different concentrations $(0,1 \mathrm{mM}, 5 \mathrm{mM})$ of RGD peptide mixed polyethylene glycol hydrogel, the $1 \mathrm{mM}$ RGD was most conducive to the formation of human mesenchymal stem cells in vitro. Mechanical stimulation may cause the reaction between RGD and cells. Without dynamic loading, RGD had a negative effect on chondrocyte phenotype. After dynamic compression, chondrocyte phenotype and proteoglycan synthesis increased with the increase of RGD concentration (Villanueva et al., 2009). Moreover, physicochemical properties may influence chondrogenic differentiation of cells and soft hydrogels are more conducive to chondrogenesis differentiation (Callahan et al., 2013a; Carrion et al., 2016). Another interesting phenomenon is the time response of RGD to cells. RGD promotes the survival of hMSC encapsulated in PEG gel, and can induce the early stage of cartilage formation. Its persistence would limit the complete differentiation of cells (Salinas and Anseth, 2008; Kloxin et al., 2009).

In conclusion, different RGD adhesion peptide sequences, spatial distribution of RGD polypeptide, cells, concentrations of RGD polypeptide, mechanical stimulation, and even time response all affect chondrogenic differentiation. More highquality studies are needed to confirm this phenomenon.

\section{CONCLUSION}

RGD is a cell adhesion sequence found in extracellular matrix. There are many kinds of structures, and different structures may play different roles. At present, RGD sequences that are widely used 
in the field of bone and cartilage repair include RGDS, GRGDS, c (RGDfk) and YRGDS. RGD, as a polypeptide sequence, can be synthesized in many ways, such as: enzyme-catalyzed synthesis, solid phase synthesis and liquid phase synthesis. They have their own advantages and disadvantages, and the common synthesis method is solid phase synthesis. Integrin seems to play an important role in the bone and cartilage repair, its one of the important mechanisms of the RGD polypeptides action. There are eight integrins that recognize RGD sequences in natural ligands. The $\alpha 5 \beta 1$ and $\alpha v \beta 3$ integrins play the main roles. The role of integrin in bone and cartilage repair is complex. In general, $\alpha 5 \beta 1$ promotes osteogenic differentiation, osteoblast proliferation and bone formation of MSCs. a $5 \beta 1$ also promotes inflammation and decomposition, leading to cartilage matrix degradation. av $\beta 3$ inhibited MSCs proliferation and osteogenic differentiation and promoted bone resorption. Finally, inhibition of av $\beta 3$ significantly inhibited OA inflammation. At present, the application of RGD polypeptide in bone tissue engineering and cartilage tissue engineering is not in-depth enough, and it is still very controversial whether RGD polypeptide can promote osteogenesis or cartilage formation. The different results may be related to the structural sequence of RGD, concentration, spatial structure, time effect, mechanical stimulation, and distribution of integrins on different cells. In conclusion, the application of RGD in

\section{REFERENCES}

Alipour, M., Baneshi, M., Hosseinkhani, S., Mahmoudi, R., Jabari Arabzadeh, A., Akrami, M., et al. (2020). Recent Progress in Biomedical Applications of RGDBased Ligand: From Precise Cancer Theranostics to Biomaterial Engineering: A Systematic Review. J. Biomed. Mater. Res. 108 (4), 839-850. doi:10.1002/ jbm.a.36862

Almonte-Becerril, M., Costell, M., and Kouri, J. B. (2014). Changes in the Integrins Expression Are Related with the Osteoarthritis Severity in an Experimental Animal Model in Rats. J. Orthop. Res. 32 (9), 1161-1166. doi:10.1002/jor.22649

Attur, M. G., Dave, M. N., Clancy, R. M., Patel, I. R., Abramson, S. B., and Amin, A. R. (2000). Functional Genomic Analysis in Arthritis-Affected Cartilage: YinYang Regulation of Inflammatory Mediators by $\alpha 5 \beta 1$ and $\alpha \mathrm{V} \beta 3$ Integrins. J. Immunol. 164 (5), 2684-2691. doi:10.4049/jimmunol.164.5.2684

Barczyk, M., Carracedo, S., and Gullberg, D. (2010). Integrins. Cell Tissue Res 339 (1), 269-280. doi:10.1007/s00441-009-0834-6

Barnett, R. (2018). Osteoarthritis. The Lancet 391 (10134), 1985. doi:10.1016/ S0140-6736(18)31064-X

Bell, B. F., Schuler, M., Tosatti, S., Textor, M., Schwartz, Z., and Boyan, B. D. (2011). Osteoblast Response to Titanium Surfaces Functionalized with Extracellular Matrix Peptide Biomimetics. Clin. Oral Implants Res. 22 (8), 865-872. doi:10.1111/j.1600-0501.2010.02074.x

Benoit, D. S. W., and Anseth, K. S. (2005). The Effect on Osteoblast Function of Colocalized RGD and PHSRN Epitopes on PEG Surfaces. Biomaterials 26 (25), 5209-5220. doi:10.1016/j.biomaterials.2005.01.045

Bogdanowich-Knipp, S. J., Chakrabarti, S., Siahaan, T. J., Williams, T. D., and Dillman, R. K. (1999). Solution Stability of Linear vs. Cyclic RGD Peptides. J. Pept. Res. 53 (5), 530-541. doi:10.1034/j.1399-3011.1999.00052.x

Bryant, S. J., Nicodemus, G. D., and Villanueva, I. (2008). Designing 3D Photopolymer Hydrogels to Regulate Biomechanical Cues and Tissue Growth for Cartilage Tissue Engineering. Pharm. Res. 25 (10), 2379-2386. doi:10.1007/s11095-008-9619-y

Burdick, J. A., and Anseth, K. S. (2002). Photoencapsulation of Osteoblasts in Injectable RGD-Modified PEG Hydrogels for Bone Tissue Engineering. Biomaterials 23 (22), 4315-4323. doi:10.1016/s0142-9612(02)00176-x bone and cartilage tissue engineering needs further research, especially to explore its mechanism with integrin. In addition, the time responsiveness, mechanical responsiveness, and repair ability of RGD in complex environment in vivo also need further research.

\section{AUTHOR CONTRIBUTIONS}

MY, Z-CZ, and YL contributed equally to this review paper. F-ZY and J-KY conceived the content of paper. MY, Z-CZ, and F-ZY wrote the article and YL collected the literatures. MY draw all the flow charts. YL, Y-RC, R-HD, and Z-NZ provided important revision suggestions. All authors reviewed and commented on the manuscript.

\section{FUNDING}

This research was funded by the National Natural Science Foundation of China (51920105006, 81630056, 51973226, and 51773004) and the Construction of a Basic Public Service Platform for Industrial Technology in the Field of Advanced Medical Equipment (0714-EMTC-02-00897).

Cacciari, B., and Spalluto, G. (2005). Non Peptidic av $\beta 3$ Antagonists: Recent Developments. Cmc 12 (1), 51-70. doi:10.2174/0929867053363522

Callahan, L. A. S., Childers, E. P., Bernard, S. L., Weiner, S. D., and Becker, M. L. (2013b). Maximizing Phenotype Constraint and Extracellular Matrix Production in Primary Human Chondrocytes Using Arginine-GlycineAspartate Concentration Gradient Hydrogels. Acta Biomater. 9 (7), 7420-7428. doi:10.1016/j.actbio.2013.04.005

Callahan, L. A. S., Ganios, A. M., Childers, E. P., Weiner, S. D., and Becker, M. L. (2013a). Primary Human Chondrocyte Extracellular Matrix Formation and Phenotype Maintenance Using RGD-Derivatized PEGDM Hydrogels Possessing a Continuous Young's Modulus Gradient. Acta Biomater. 9 (4), 6095-6104. doi:10.1016/j.actbio.2012.12.028

Callahan, L. A. S., Policastro, G. M., Bernard, S. L., Childers, E. P., Boettcher, R., and Becker, M. L. (2013c). Influence of Discrete and Continuous Culture Conditions on Human Mesenchymal Stem Cell Lineage Choice in RGD Concentration Gradient Hydrogels. Biomacromolecules 14 (9), 3047-3054. doi: $10.1021 / \mathrm{bm} 4006112$

Candela, M. E., Wang, C., Gunawardena, A. T., Zhang, K., Cantley, L., Yasuhara, R., et al. (2016). Alpha 5 Integrin Mediates Osteoarthritic Changes in Mouse Knee Joints. PLoS One 11 (6), e0156783. doi:10.1371/journal.pone.0156783

Cao, B., Peng, R., Li, Z., and Ding, J. (2014). Effects of Spreading Areas and Aspect Ratios of Single Cells on Dedifferentiation of Chondrocytes. Biomaterials 35 (25), 6871-6881. doi:10.1016/j.biomaterials.2014.04.107

Carles-Carner, M., Saleh, L. S., and Bryant, S. J. (2018). The Effects of Hydroxyapatite Nanoparticles Embedded in a MMP-Sensitive Photoclickable PEG Hydrogel on Encapsulated MC3T3-E1 Pre-osteoblasts. Biomed. Mater. 13 (4), 045009. doi:10.1088/1748-605X/aabb31

Carrion, B., Souzanchi, M. F., Wang, V. T., Tiruchinapally, G., Shikanov, A., Putnam, A. J., et al. (2016). The Synergistic Effects of Matrix Stiffness and Composition on the Response of Chondroprogenitor Cells in a 3D Precondensation Microenvironment. Adv. Healthc. Mater. 5 (10), 1192-1202. doi:10.1002/adhm.201501017

Chahal, A. S., Schweikle, M., Lian, A.-M., Reseland, J. E., Haugen, H. J., and Tiainen, H. (2020). Osteogenic Potential of Poly(ethylene Glycol)-Amorphous Calcium Phosphate Composites on Human Mesenchymal Stem Cells. J. Tissue Eng. 11, 204173142092684. doi:10.1177/2041731420926840 
Cheng, S.-L., Lai, C.-F., Blystone, S. D., and Avioli, L. V. (2001). Bone Mineralization and Osteoblast Differentiation Are Negatively Modulated by Integrin av $\beta 3$. J. Bone Miner. Res. 16 (2), 277-288. doi:10.1359/ jbmr.2001.16.2.277

Chin, S. Y., Poh, Y. C., Kohler, A.-C., and Sia, S. K. (2018). An Additive Manufacturing Technique for the Facile and Rapid Fabrication of HydrogelBased Micromachines with Magnetically Responsive Components. J. Vis. Exp. 137, 56727. doi:10.3791/56727

Colombo, M., and Bianchi, A. (2010). Click Chemistry for the Synthesis of RGDContaining Integrin Ligands. Molecules 15 (1), 178-197. doi:10.3390/ molecules 15010178

Daly, A. C., Freeman, F. E., Gonzalez-Fernandez, T., Critchley, S. E., Nulty, J., and Kelly, D. J. (2017). 3D Bioprinting for Cartilage and Osteochondral Tissue Engineering. Adv. Healthc. Mater. 6 (22), 1700298. doi:10.1002/adhm.201700298

Dard, M., Sewing, A., Meyer, J., Verrier, S., Roessler, S., and Scharnweber, D. (2000). Tools for Tissue Engineering of Mineralized Oral Structures. Clin. Oral Investig. 4 (2), 126-129. doi:10.1007/s007840050128

de Jonge, L. T., Leeuwenburgh, S. C. G., Wolke, J. G. C., and Jansen, J. A. (2008). Organic-Inorganic Surface Modifications for Titanium Implant Surfaces. Pharm. Res. 25 (10), 2357-2369. doi:10.1007/s11095-008-9617-0

Deng, C., Xu, C., Zhou, Q., and Cheng, Y. (2019). Advances of Nanotechnology in Osteochondral Regeneration. WIREs Nanomed Nanobiotechnol 11 (6), e1576. doi:10.1002/wnan.1576

Deng, C., Zhang, Q., He, P., Zhou, B., He, K., Sun, X., et al. (2021). Targeted Apoptosis of Macrophages and Osteoclasts in Arthritic Joints Is Effective against Advanced Inflammatory Arthritis. Nat. Commun. 12 (1), 2174. doi:10.1038/s41467-021-22454-Z

Di Palma, J. A., Bhandari, R., Cleveland, M. V., Mishkin, D. S., Tesoriero, J., Hall, S., et al. (2021). A Safety and Efficacy Comparison of a New Sulfate-Based Tablet Bowel Preparation versus a PEG and Ascorbate Comparator in Adult Subjects Undergoing Colonoscopy. Am. J. Gastroenterol. 116 (2), 319-328. doi:10.14309/ajg.0000000000001020

Dufour, C., Holy, X., and Marie, P. J. (2008). Transforming Growth Factor- $\beta$ Prevents Osteoblast Apoptosis Induced by Skeletal Unloading via PI3K/Akt, Bcl-2, and Phospho-Bad Signaling. Am. J. Physiology-Endocrinology Metab. 294 (4), E794-E801. doi:10.1152/ajpendo.00791.2007

Ellis, S. J., and Tanentzapf, G. (2010). Integrin-mediated Adhesion and Stem-CellNiche Interactions. Cel Tissue Res 339 (1), 121-130. doi:10.1007/s00441-0090828-4

Elmengaard, B., Bechtold, J. E., and Søballe, K. (2005). In Vivo effects of RGDCoated Titanium Implants Inserted in Two Bone-gap Models. J. Biomed. Mater. Res. 75A (2), 249-255. doi:10.1002/jbm.a.30301

Ferris, D. M., Moodie, G. D., Dimond, P. M., Gioranni, C. W., Ehrlich, M. G., and Valentini, R. F. (1999). RGD-coated Titanium Implants Stimulate Increased Bone Formation In Vivo. Biomaterials 20 (23-24), 2323-2331. doi:10.1016/ s0142-9612(99)00161-1

Frochot, C., Stasio, B. D., Vanderesse, R., Belgy, M.-J., Dodeller, M., Guillemin, F., et al. (2007). Interest of RGD-Containing Linear or Cyclic Peptide Targeted Tetraphenylchlorin as Novel Photosensitizers for Selective Photodynamic Activity. Bioorg. Chem. 35 (3), 205-220. doi:10.1016/j.bioorg.2006.11.005

Gao, G., Yonezawa, T., Hubbell, K., Dai, G., and Cui, X. (2015). Inkjet-bioprinted Acrylated Peptides and PEG Hydrogel with Human Mesenchymal Stem Cells Promote Robust Bone and Cartilage Formation with Minimal Printhead Clogging. Biotechnol. J. 10 (10), 1568-1577. doi:10.1002/biot.201400635

Goessler, U., Bugert, P., Bieback, K., Stern-Straeter, J., Bran, G., Hörmann, K., et al. (2008). Integrin Expression in Stem Cells from Bone Marrow and Adipose Tissue during Chondrogenic Differentiation. Int. J. Mol. Med. 21 (3), 271-279. doi:10.3892/ijmm.21.3.271

Guan, Z.-Y., Wu, C.-Y., Wu, J.-T., Tai, C.-H., Yu, J., and Chen, H.-Y. (2016). Multifunctional and Continuous Gradients of Biointerfaces Based on Dual Reverse Click Reactions. ACS Appl. Mater. Inter. 8 (22), 13812-13818. doi:10.1021/acsami.6b03908

Hamidouche, Z., Fromigué, O., Ringe, J., Häupl, T., Vaudin, P., Pagès, J.-C., et al. (2009). Priming Integrin 5 Promotes Human Mesenchymal Stromal Cell Osteoblast Differentiation and Osteogenesis. Proc. Natl. Acad. Sci. 106 (44), 18587-18591. doi:10.1073/pnas.0812334106

Heller, M., Kumar, V. V., Pabst, A., Brieger, J., Al-Nawas, B., and Kämmerer, P. W. (2018). Osseous Response on Linear and Cyclic RGD-Peptides Immobilized on
Titanium Surfaces In Vitro and In Vivo. J. Biomed. Mater. Res. 106 (2), 419-427. doi:10.1002/jbm.a.36255

Horton, M. A. (2001). Integrin Antagonists as Inhibitors of Bone Resorption: Implications for Treatment. Proc. Nutr. Soc. 60 (2), 275-281. doi:10.1079/ pns200079

Horton, M. A. (1997). The av $\beta 3$ Integrin “Vitronectin Receptor". Int. J. Biochem. Cel Biol. 29 (5), 721-725. doi:10.1016/s1357-2725(96)00155-0

Huang, Y.-B., Xiao, Y.-P., Wang, H., Hou, R.-Z., Zhang, N., Wu, X.-X., et al. (2005). Chemo-enzymatic Synthesis of Tripeptide RGD Diamide in Organic Solvents. J. Biotechnol. 116 (1), 51-59. doi:10.1016/j.jbiotec.2004.10.004

Jäger, M., Böge, C., Janissen, R., Rohrbeck, D., Hülsen, T., Lensing-Höhn, S., et al. (2013). Osteoblastic Potency of Bone Marrow Cells Cultivated on Functionalized Biometals with Cyclic RGD-Peptide. J. Biomed. Mater. Res. 101 (10), 2905-2914. doi:10.1002/jbm.a.34590

Jiang, S., Wang, M., and He, J. (2021). A Review of Biomimetic Scaffolds for Bone Regeneration: Toward a Cell-free Strategy. Bioeng. Transl Med. 6 (2), e10206. doi:10.1002/btm2.10206

Kim, H. D., Amirthalingam, S., Kim, S. L., Lee, S. S., Rangasamy, J., and Hwang, N. S. (2017). Biomimetic Materials and Fabrication Approaches for Bone Tissue Engineering. Adv. Healthc. Mater. 6 (23), 1700612. doi:10.1002/ adhm.201700612

Kim, H. D., Heo, J., Hwang, Y., Kwak, S.-Y., Park, O. K., Kim, H., et al. (2015). Extracellular-matrix-based and Arg-Gly-Asp-Modified Photopolymerizing Hydrogels for Cartilage Tissue Engineering. Tissue Eng. A 21 (3-4), 757-766. doi:10.1089/ten.TEA.2014.0233

Kim, H. J., You, S. J., Yang, D. H., Eun, J., Park, H. K., Kim, M. S., et al. (2020). Injectable Hydrogels Based on MPEG-PCL-RGD and BMSCs for Bone Tissue Engineering. Biomater. Sci. 8 (15), 4334-4345. doi:10.1039/d0bm00588f

Kloxin, A. M., Kasko, A. M., Salinas, C. N., and Anseth, K. S. (2009). Photodegradable Hydrogels for Dynamic Tuning of Physical and Chemical Properties. Science 324 (5923), 59-63. doi:10.1126/science.1169494

Kong, L., Alves, C. S., Hou, W., Qiu, J., Möhwald, H., Tomás, H., et al. (2015). RGD Peptide-Modified Dendrimer-Entrapped Gold Nanoparticles Enable Highly Efficient and Specific Gene Delivery to Stem Cells. ACS Appl. Mater. Inter. 7 (8), 4833-4843. doi:10.1021/am508760w

Krishnan, Y., and Grodzinsky, A. J. (2018). Cartilage Diseases. Matrix Biol. 71-72, 51-69. doi:10.1016/j.matbio.2018.05.005

Kudva, A. K., Luyten, F. P., and Patterson, J. (2017). Initiating Human Articular Chondrocyte Re-differentiation in a 3D System after 2D Expansion. J. Mater. Sci. Mater. Med. 28 (10), 156. doi:10.1007/s10856-017-5968-6

Kudva, A. K., Luyten, F. P., and Patterson, J. (2018a). RGD-functionalized Polyethylene Glycol Hydrogels Support Proliferation Andin Vitrochondrogenesis of Human Periosteum-Derived Cells. J. Biomed. Mater. Res. 106 (1), 33-42. doi:10.1002/jbm.a.36208

Kudva, A., Luyten, F., and Patterson, J. (2018b). In Vitro Screening of Molecularly Engineered Polyethylene Glycol Hydrogels for Cartilage Tissue Engineering Using Periosteum-Derived and ATDC5 Cells. Ijms 19 (11), 3341. doi:10.3390/ ijms19113341

Kuijpers, B. H. M., Groothuys, S., Soede, A. C., Laverman, P., Boerman, O. C., van Delft, F. L., et al. (2007). Preparation and Evaluation of Glycosylated ArginineGlycine-Aspartate (RGD) Derivatives for Integrin Targeting. Bioconjug. Chem. 18 (6), 1847-1854. doi:10.1021/bc700154u

Kumagai, H., Tajima, M., Ueno, Y., Giga-Hama, Y., and Ohba, M. (1991). Effect of Cyclic RGD Peptide on Cell Adhesion and Tumor Metastasis. Biochem. Biophysical Res. Commun. 177 (1), 74-82. doi:10.1016/0006-291x(91)91950-h

Lee, S., Choi, E., Cha, M.-J., and Hwang, K.-C. (20152015). Cell Adhesion and Long-Term Survival of Transplanted Mesenchymal Stem Cells: a Prerequisite for Cell Therapy. Oxidative Med. Cell Longevity 2015, 1-9. doi:10.1155/2015/ 632902

Li, S., Wang, X., Cao, B., Ye, K., Li, Z., and Ding, J. (2015a). Effects of Nanoscale Spatial Arrangement of Arginine-Glycine-Aspartate Peptides on Dedifferentiation of Chondrocytes. Nano Lett. 15 (11), 7755-7765. doi:10.1021/acs.nanolett.5b04043

Li, Z., Cao, B., Wang, X., Ye, K., Li, S., and Ding, J. (2015b). Effects of RGD Nanospacing on Chondrogenic Differentiation of Mesenchymal Stem Cells. J. Mater. Chem. B 3 (26), 5197-5209. doi:10.1039/c5tb00455a

Lin, Y., Huang, S., Zou, R., Gao, X., Ruan, J., Weir, M. D., et al. (2019). Calcium Phosphate Cement Scaffold with Stem Cell Co-culture and Prevascularization 
for Dental and Craniofacial Bone Tissue Engineering. Dental Mater. 35 (7), 1031-1041. doi:10.1016/j.dental.2019.04.009

Liu, S. Q., Tian, Q., Wang, L., Hedrick, J. L., Hui, J. H. P., Yang, Y. Y., et al. (2010). Injectable Biodegradable Poly(ethylene Glycol)/RGD Peptide Hybrid Hydrogels for In Vitro Chondrogenesis of Human Mesenchymal Stem Cells. Macromol. Rapid Commun. 31 (13), 1148-1154. doi:10.1002/marc.200900818

Liu, Y., Ma, L., Zhou, H., Zhu, X., Yu, Q., Chen, X., et al. (2018). Polypeptide NanoSe Targeting Inflammation and Theranostic Rheumatoid Arthritis by Antiangiogenic and NO Activating AMPKa Signaling Pathway. J. Mater. Chem. $B 6$ (21), 3497-3514. doi:10.1039/c8tb00080h

Loeser, R. F. (2014). Integrins and Chondrocyte-Matrix Interactions in Articular Cartilage. Matrix Biol. 39, 11-16. doi:10.1016/j.matbio.2014.08.007

Marsico, G., Russo, L., Quondamatteo, F., and Pandit, A. (2018). Glycosylation and Integrin Regulation in Cancer. Trends Cancer 4 (8), 537-552. doi:10.1016/ j.trecan.2018.05.009

Martino, M. M., Mochizuki, M., Rothenfluh, D. A., Rempel, S. A., Hubbell, J. A., and Barker, T. H. (2009). Controlling Integrin Specificity and Stem Cell Differentiation in 2D and 3D Environments through Regulation of Fibronectin Domain Stability. Biomaterials 30 (6), 1089-1097. doi:10.1016/ j.biomaterials.2008.10.047

Moursi, A. M., Damsky, C. H., Lull, J., Zimmerman, D., Doty, S. B., Aota, S., et al. (1996). Fibronectin Regulates Calvarial Osteoblast Differentiation. J. Cel Sci. 109 (6), 1369-1380.

Nam, S., Stowers, R., Lou, J., Xia, Y., and Chaudhuri, O. (2019). Varying PEG Density to Control Stress Relaxation in Alginate-PEG Hydrogels for 3D Cell Culture Studies. Biomaterials 200, 15-24. doi:10.1016/j.biomaterials.2019.02.004

Nuttelman, C., Tripodi, M., and Anseth, K. (2005). Synthetic Hydrogel Niches that Promote hMSC Viability. Matrix Biol. 24 (3), 208-218. doi:10.1016/ j.matbio.2005.03.004

Ostergaard, K., Salter, D. M., Petersen, J., Bendtzen, K., Hvolris, J., and Andersen, C. B. (1998). Expression of Alpha and Beta Subunits of the Integrin Superfamily in Articular Cartilage from Macroscopically normal and Osteoarthritic Human Femoral Heads. Ann. Rheum. Dis. 57 (5), 303-308. doi:10.1136/ard.57.5.303

Pan, H., Zheng, Q., Yang, S., and Guo, X. (2014). Effects of Functionalization of PLGA-[Asp-PEG]ncopolymer Surfaces with Arg-Gly-Asp Peptides, Hydroxyapatite Nanoparticles, and BMP-2-Derived Peptides on Cell Behaviorin Vitro. J. Biomed. Mater. Res. 102 (12), a-n. doi:10.1002/jbm.a.35129

Paxton, J. Z., Donnelly, K., Keatch, R. P., and Baar, K. (2009). Engineering the Bone-Ligament Interface Using Polyethylene Glycol Diacrylate Incorporated with Hydroxyapatite. Tissue Eng. Part A 15 (6), 1201-1209. doi:10.1089/ ten.tea.2008.0105

Peng, R., Yao, X., and Ding, J. (2011). Effect of Cell Anisotropy on Differentiation of Stem Cells on Micropatterned Surfaces through the Controlled Single Cell Adhesion. Biomaterials 32 (32), 8048-8057. doi:10.1016/ j.biomaterials.2011.07.035

Pierschbacher, M. D., and Ruoslahti, E. (1984). Cell Attachment Activity of Fibronectin Can Be Duplicated by Small Synthetic Fragments of the Molecule. Nature 309 (5963), 30-33. doi:10.1038/309030a0

Pritzker, K. P. H., Gay, S., Jimenez, S. A., Ostergaard, K., Pelletier, J.-P., Revell, P. A., et al. (2006). Osteoarthritis Cartilage Histopathology: Grading and Staging. Osteoarthritis and Cartilage 14 (1), 13-29. doi:10.1016/j.joca.2005.07.014

Rahimi, M., Charmi, G., Matyjaszewski, K., Banquy, X., and Pietrasik, J. (2021). Recent Developments in Natural and Synthetic Polymeric Drug Delivery Systems Used for the Treatment of Osteoarthritis. Acta Biomater. 123, 31-50. doi:10.1016/j.actbio.2021.01.003

Reid, B., Afzal, J. M., Mccartney, A. M., Abraham, M. R., O’Rourke, B., and Elisseeff, J. H. (2013). Enhanced Tissue Production through Redox Control in Stem Cell-Laden Hydrogels. Tissue Eng. Part A 19 (17-18), 2014-2023. doi:10.1089/ten.TEA.2012.0515

Richbourg, N. R., Peppas, N. A., and Sikavitsas, V. I. (2019). Tuning the Biomimetic Behavior of Scaffolds for Regenerative Medicine through Surface Modifications. J. Tissue Eng. Regen. Med. 13 (8), 1275-1293. doi:10.1002/term.2859

Ruoslahti, E. (1996). RGD and Other Recognition Sequences for Integrins. Annu. Rev. Cel Dev. Biol. 12 (1), 697-715. doi:10.1146/annurev.cellbio.12.1.697

Salinas, C. N., and Anseth, K. S. (2008). The Enhancement of Chondrogenic Differentiation of Human Mesenchymal Stem Cells by Enzymatically Regulated RGD Functionalities. Biomaterials 29 (15), 2370-2377. doi:10.1016/ j.biomaterials.2008.01.035
Salinas, C. N., Cole, B. B., Kasko, A. M., and Anseth, K. S. (2007). Chondrogenic Differentiation Potential of Human Mesenchymal Stem Cells Photoencapsulated within Poly(Ethylene Glycol)-Arginine-Glycine-Aspartic Acid-Serine Thiol-Methacrylate Mixed-Mode Networks. Tissue Eng. 13 (5), 1025-1034. doi:10.1089/ten.2006.0126

Schneider, G. B., Zaharias, R., and Stanford, C. (2001). Osteoblast Integrin Adhesion and Signaling Regulate Mineralization. J. Dent. Res. 80 (6), 1540-1544. doi:10.1177/00220345010800061201

Shadjou, N., Hasanzadeh, M., and Khalilzadeh, B. (2018). Graphene Based Scaffolds on Bone Tissue Engineering. Bioengineered 9 (1), 38-47. doi:10.1080/21655979.2017.1373539

Shen, B., Vardy, K., Hughes, P., Tasdogan, A., Zhao, Z., Yue, R., et al. (2019). Integrin Alpha11 Is an Osteolectin Receptor and Is Required for the Maintenance of Adult Skeletal Bone Mass. eLife 8, e42274. doi:10.7554/ eLife. 42274

Steinmetz, N. J., and Bryant, S. J. (2011). The Effects of Intermittent Dynamic Loading on Chondrogenic and Osteogenic Differentiation of Human Marrow Stromal Cells Encapsulated in RGD-Modified Poly(ethylene Glycol) Hydrogels. Acta Biomater. 7 (11), 3829-3840. doi:10.1016/j.actbio.2011.06.031

Sulyok, G. A. G., Gibson, C., Goodman, S. L., Hölzemann, G., Wiesner, M., and Kessler, H. (2001). Solid-Phase Synthesis of a Nonpeptide RGD Mimetic Library: New Selective av $\beta 3$ Integrin Antagonists. J. Med. Chem. 44 (12), 1938-1950. doi:10.1021/jm0004953

Takada, Y., Ye, X., and Simon, S. (2007). The Integrins. Genome Biol. 8 (5), 215. doi:10.1186/gb-2007-8-5-215

Tang, J., Peng, R., and Ding, J. (2010). The Regulation of Stem Cell Differentiation by Cell-Cell Contact on Micropatterned Material Surfaces. Biomaterials 31 (9), 2470-2476. doi:10.1016/j.biomaterials.2009.12.006

Tao, T., Li, Y., Gui, C., Ma, Y., Ge, Y., Dai, H., et al. (2018). Fibronectin Enhances Cartilage Repair by Activating Progenitor Cells through Integrin $\alpha 5 \beta 1$ Receptor. Tissue Eng. Part A 24 (13-14), 1112-1124. doi:10.1089/ ten.tea.2017.0322

Thoma, D. S., Subramani, K., Weber, F. E., Luder, H. U., Hämmerle, C. H. F., and Jung, R. E. (2011). Biodegradation, Soft and Hard Tissue Integration of Various Polyethylene Glycol Hydrogels: a Histomorphometric Study in Rabbits. Clin. Oral Implants Res. 22 (11), 1247-1254. doi:10.1111/j.1600-0501.2010.02075.x

Tosatti, S., Schwartz, Z., Campbell, C., Cochran, D. L., Vandevondele, S., Hubbell, J. A., et al. (2004). RGD-containing Peptide GCRGYGRGDSPG Reduces Enhancement of Osteoblast Differentiation by poly(L-Lysine)-GraftPoly(ethylene Glycol)-Coated Titanium Surfaces. J. Biomed. Mater. Res. 68A (3), 458-472. doi:10.1002/jbm.a.20082

Verrier, S., Pallu, S., Bareille, R., Jonczyk, A., Meyer, J., Dard, M., et al. (2002). Function of Linear and Cyclic RGD-Containing Peptides in Osteoprogenitor Cells Adhesion Process. Biomaterials 23 (2), 585-596. doi:10.1016/s01429612(01)00145-4

Villanueva, I., Weigel, C. A., and Bryant, S. J. (2009). Cell-matrix Interactions and Dynamic Mechanical Loading Influence Chondrocyte Gene Expression and Bioactivity in PEG-RGD Hydrogels. Acta Biomater. 5 (8), 2832-2846. doi:10.1016/j.actbio.2009.05.039

Vonwil, D., Schuler, M., Schuler, M., Barbero, A., Ströbel, S., Wendt, D., et al. (2010). An RGD-Restricted Substrate Interface Is Sufficient for the Adhesion, Growth and Cartilage Forming Capacity of Human Chondrocytes. $e C M 20$, 316-328. doi:10.22203/ecm.v020a26

Wang, F., Guo, C., Yang, Q., Li, C., Zhao, P., Xia, Q., et al. (2021). Protein Composites from Silkworm Cocoons as Versatile Biomaterials. Acta Biomater. 121, 180-192. doi:10.1016/j.actbio.2020.11.037

Wang, Q., Onuma, K., Liu, C., Wong, H., Bloom, M. S., Elliott, E. E., et al. (2019). Dysregulated Integrin $\alpha \mathrm{V} \beta 3$ and CD47 Signaling Promotes Joint Inflammation, Cartilage Breakdown, and Progression of Osteoarthritis. JCI Insight 4 (18), e128616. doi:10.1172/jci.insight.128616

Wang, W., Wu, Q., Pasuelo, M., Mcmurray, J. S., and Li, C. (2005). Probing for Integrin av $\beta 3$ Binding of RGD Peptides Using Fluorescence Polarization. Bioconjug. Chem. 16 (3), 729-734. doi:10.1021/bc049763s

Wang, Y., Malcolm, D. W., and Benoit, D. S. W. (2017). Controlled and Sustained Delivery of siRNA/NPs from Hydrogels Expedites Bone Fracture Healing. Biomaterials 139, 127-138. doi:10.1016/j.biomaterials.2017.06.001

Wei, L., Zhou, Q., Tian, H., Su, Y., Fu, G.-h., and Sun, T. (2020). Integrin $\beta 3$ Promotes Cardiomyocyte Proliferation and Attenuates Hypoxia-Induced 
Apoptosis via Regulating the PTEN/Akt/mTOR and ERK1/2 Pathways. Int. J. Biol. Sci. 16 (4), 644-654. doi:10.7150/ijbs.39414

Wong, D. S. H., Li, J., Yan, X., Wang, B., Li, R., Zhang, L., et al. (2017). Magnetically Tuning Tether Mobility of Integrin Ligand Regulates Adhesion, Spreading, and Differentiation of Stem Cells. Nano Lett. 17 (3), 1685-1695. doi:10.1021/ acs.nanolett.6b04958

Woods, V. L., Schreck, P. J., Gesink, D. S., Pacheco, H. O., Amiel, D., Akeson, W. H., et al. (1994). Integrin Expression by Human Articular Chondrocytes. Arthritis Rheum. 37 (4), 537-544. doi:10.1002/art.1780370414

Yang, F., Williams, C. G., Wang, D.-a., Lee, H., Manson, P. N., and Elisseeff, J. (2005). The Effect of Incorporating RGD Adhesive Peptide in Polyethylene Glycol Diacrylate Hydrogel on Osteogenesis of Bone Marrow Stromal Cells. Biomaterials 26 (30), 5991-5998. doi:10.1016/j.biomaterials.2005.03.018

Ye, K., Cao, L., Li, S., Yu, L., and Ding, J. (2016). Interplay of Matrix Stiffness and Cell-Cell Contact in Regulating Differentiation of Stem Cells. ACS Appl. Mater. Inter. 8 (34), 21903-21913. doi:10.1021/acsami.5b09746

Ye, K., Wang, X., Cao, L., Li, S., Li, Z., Yu, L., et al. (2015). Matrix Stiffness and Nanoscale Spatial Organization of Cell-Adhesive Ligands Direct Stem Cell Fate. Nano Lett. 15 (7), 4720-4729. doi:10.1021/acs.nanolett.5b01619

Zhang, B., Huang, J., and Narayan, R. J. (2020). Gradient Scaffolds for Osteochondral Tissue Engineering and Regeneration. J. Mater. Chem. B 8 (36), 8149-8170. doi:10.1039/d0tb00688b

Zhang, J., Mujeeb, A., Du, Y., Lin, J., and Ge, Z. (2015). Probing Cell-Matrix Interactions in RGD-Decorated Macroporous Poly (Ethylene Glycol)
Hydrogels for 3D Chondrocyte Culture. Biomed. Mater. 10 (3), 035016. doi:10.1088/1748-6041/10/3/035016

Zhang, W., Zhu, Y., Li, J., Guo, Q., Peng, J., Liu, S., et al. (2016). Cell-Derived Extracellular Matrix: Basic Characteristics and Current Applications in Orthopedic Tissue Engineering. Tissue Eng. B: Rev. 22 (3), 193-207. doi:10.1089/ten.TEB.2015.0290

Conflict of Interest: The authors declare that the research was conducted in the absence of any commercial or financial relationships that could be construed as a potential conflict of interest.

Publisher's Note: All claims expressed in this article are solely those of the authors and do not necessarily represent those of their affiliated organizations, or those of the publisher, the editors and the reviewers. Any product that may be evaluated in this article, or claim that may be made by its manufacturer, is not guaranteed or endorsed by the publisher.

Copyright $\odot 2021$ Yang, Zhang, Liu, Chen, Deng, Zhang, Yu and Yuan. This is an open-access article distributed under the terms of the Creative Commons Attribution License (CC BY). The use, distribution or reproduction in other forums is permitted, provided the original author(s) and the copyright owner(s) are credited and that the original publication in this journal is cited, in accordance with accepted academic practice. No use, distribution or reproduction is permitted which does not comply with these terms. 